\title{
HOSPITAL INFECTION CONTROL AND BEHAVIOUR OF OPERATING ROOM STAFF
}

\author{
Daniela Lo Giudice ${ }^{1}$, Giuseppe Trimarchi ${ }^{2}$, Vincenza La Fauci ${ }^{1}$, Raffaele Squeri ${ }^{1}$, Sebastiano Calimeri ${ }^{1}$ \\ ${ }^{1}$ Department of Biomedical and Dental Sciences and Morphofunctional Imaging, University of Messina, Messina, Italy \\ ${ }^{2}$ SIR - Faculty of Medicine and Surgery, University of Messina, Messina, Italy
}

\begin{abstract}
SUMMARY
Objectives: Surgical site infections (SSIs) are a frequent complication of surgical procedures and one of the most common forms of hospital acquired infection (HAl). National/international guidelines and recommendations have been issued for prevention. The objective of this study was to observe the behaviour of healthcare workers engaged in surgical procedures and hence assess compliance with SSI guidelines.

Methods: An observational descriptive study was conducted at a University hospital in southern Italy. A specifically designed form was used to record the actions of the surgical team during randomly selected surgical operations. Observations comprised the use of surgical attire, the frequency of doors opening and the number of staff in the operating room.

Results: A total of 308 operating room personnel was observed during 402 surgical procedures: 127 surgeons (41\%), 39 anaesthesiologists (13\%), 62 nurses (20\%) and 80 students in training (26\%). $96 \%$ of the surgical team wore scrubs, $93 \%$ of health workers wore a mask and of these $78 \%$ wore it correctly in order to completely cover the nose, mouth and beard (when present), $99 \%$ wore a cap (only in $48 \%$ was the hair completely covered), $50 \%$ of the operators wore gloves, $95 \%$ wore shoes dedicated to the operating theater and $23 \%$ also wore shoe covers, $56 \%$ wore gowns, and $22 \%$ had eye protection. Furthermore, the average number of health personnel in the operating theater was 8 , the doors remained closed in 261 (65\%) surgical operations.

Conclusion: As the results indicated a low adherence to international guidelines among the personnel, it is suggested that training courses should be provided to increase staff awareness on prevention and management of HAI.
\end{abstract}

Key words: practice, attitude, infection control, surgical site infection, international guidelines, operating room

Address for correspondence: D. Lo Giudice, Department of Biomedical and Dental Sciences and Morphofunctional Imaging, University of Messina, Via Consolare Valeria, 98125 Messina, Italy. E-mail address: dlogiudice@unime.it

https://doi.org/10.21101/cejph.a4932

\section{INTRODUCTION}

Healthcare associated infection (HAI) is one of the common problems in hospitals worldwide and surgical site infection (SSI) is the most frequent form related to surgical health care.

As these infections are extremely heterogeneous it is difficult to determine their epidemiology precisely. SSIs are the second most common nosocomial infections, accounting for approximately $20 \%$ of all hospital-acquired infections (1). It has been estimated that they double the cost of care and increase hospital stay by 6.5 days (2). The rate of SSIs varies widely from less than $1 \%$ in clean surgeries in patients not at risk up to $15 \%$ in intestinal surgeries in patients at risk $(3,4)$. However, this considerable variability derives not only from the type of surgery but also from the hospital, the patient and the surgeon (5).

The internationally recognized Guidelines for Prevention of Surgical Site Infection are a benchmark for the prevention of post-operative infections (6). The World Health Organization produced "Guidelines for Safe Surgery" in 2008 (7) aimed at improving the safety of surgical procedures by setting clearly defined standards and recommendations regarding standards of safety to be observed in different countries and surgical settings, reinforcing pre-, intra- and post-operative procedures.
SSIs cannot be eradicated completely but adopting satisfactory preventive measures significantly reduces the rate of infections arising from surgical complications. The most important point is to lay down and implement a systematic approach standardizing and optimizing the actions of health workers in the three phases of surgery.

The operating room (OR) is a complex environment, traditionally understood to carry a high risk of infection. The place, instruments and staff behaviour regarding access to the OR, their attire and preparation of the surgical team and antibiotic prophylaxis all play a key role in preventing infection. A further consideration is that the majority of airborne bacteria that may reach the surgical setting come from cutaneous flora or the oral cavity of personnel in the OR (8) and the amount will depend on both the number of staff and the duties they perform $(9,10)$. Thus, an efficient ventilation system is vital in order to ensure low levels of bacterial contamination by limiting the dispersion of particles as much as possible (8) as is the correct use of surgical attire and the quality of materials from which this is made $(11,12)$, correct preparation of the patient before surgery, and adequately trained staff (13). Despite the importance of all these preventive measures, studies in the literature show compliance to be very low (14). 
The aim of this study was to compare adherence to international guidelines among healthcare workers engaged in surgeries by observing their behaviour in real time in the operating room.

\section{MATERIALS AND METHOD}

An observational descriptive study was conducted from January to December 2015 at the University Hospital G. Martino in Messina, Italy.

The study assessed 402 surgical procedures selected through simple random sampling from a total of 5,637 scheduled inpatient surgeries in the above period. The sample comprised four fields of surgery: 110 general (gastrointestinal, oncological, endocrine, anorectal, geriatric, breast, and urological), 108 specialized (neuro, orthopedic and trauma, maxillofacial, ocular, ENT, and plastic), 94 maternal-infant (paediatric, gynaecological and obstetric) and 90 thoracic and vascular surgical procedures.

In order to assess compliance with international guidelines, the healthcare personnel involved in the surgical operations were monitored. These workers were observed during surgery by specially trained healthcare workers and findings were recorded using a specifically designed form. The data collected included the use and correct use of surgical attire, mask, cap, single-use gown, sterile gloves, single-use eye protection, footwear, and shoe covers. Other items monitored were the ventilation system, the position of doors during surgery and the number of staff in the OR. The monitoring took place without prior notice being given to the surgical team and lasted at least 30 min per surgery.

\section{Statistical Analyses}

Categorical variables were reported as number and percentage. The Chi-square test and partition contingency table were used and relative significance was calculated to assess the association between categorical variables. Statistical analyses were performed using SPSS 16.0 for Windows package and $\mathrm{p}<0.05$ was considered statistically significant.

\section{RESULTS}

The 402 surgical procedures monitored included 308 healthcare workers: 127 surgeons (41\%), 39 anaesthetists (13\%), 62 nurses $(20 \%)$, and 80 trainees and students $(26 \%)$.

Analysis of the data shown in Table 1 reveals that $78 \%$ of staff correctly wore a mask and $48 \%$ wore a cap that completely covered hair, $56 \%$ used a disposable gown, $50 \%$ gloves and only $22 \%$ eye protection. Not all trainees/students wore scrubs and surgical clogs while $58 \%$ wore shoe covers.

Statistically significant differences emerged between the different categories of personnel regarding the correct use of surgical attire.

Use of face masks in the categories considered yields statistically significant differences $\left(\chi^{2}=8.015 ; p=0.045\right)$ when comparing anaesthesiologists vs. surgeons, while as regards the correct use of masks a highly significant difference $\left(\chi^{2}=16.977 ; p=0.001\right)$ was found among structured health workers vs. trainees/students.

The numbers recorded for the 308 health workers as regards use of the cap do not yield significant differences $\left(\chi^{2}=6.182\right.$; $p=103$ ) whereas for the correct use of the cap a statistically significant difference was found between surgeons vs. nurses $\left(\chi^{2}=10.281 ; p=0.02\right)$.

Regarding the use of gloves, all of the 4 compared categories of operators present in the operating theater show highly significant differences $\left(\chi^{2}=222.65 ; \mathrm{p}=0.001\right)$ as in the use of shoe covers $\left(\chi^{2}=75.241 ; \mathrm{p}=0.001\right)$ and the use of gowns $\left(\chi^{2}=170.25\right.$; $\mathrm{p}=0.001)$.

No significant differences $\left(\chi^{2}=2.793 ; p=0.42\right)$ resulted for eye protection. In all surgeries monitored the turbulent air flow ventilation system was working correctly (air replacement/hour 15-20, positive differential pressures).

During the 30 minutes of observation the doors of the operating room remained closed in 261 surgical operations $(65 \%)$, while in 128 interventions $(31.8 \%)$ the doors were opened on average 2 times and in 13 interventions (3.2\%) the doors were opened more than 3 times.

The mean number of healthcare personnel in the operating room was 8 (range $4-15$ ).

Table 1. Use/correct use of personal protective equipment by healthcare workers $(N=308)$

\begin{tabular}{|l|c|c|c|c|c|c|}
\hline & $\begin{array}{c}\text { Surgeons } \\
\mathrm{n}=127(\mathbf{4 1 \% )}\end{array}$ & $\begin{array}{c}\text { Anaesthetists } \\
\mathrm{n}=39(\mathbf{1 3} \%)\end{array}$ & $\begin{array}{c}\text { Nurses } \\
\mathrm{n}=\mathbf{6 2}(\mathbf{2 0 \% )}\end{array}$ & $\begin{array}{c}\text { Trainees/students } \\
\mathrm{n}=\mathbf{8 0}(\mathbf{2 6 \% )}\end{array}$ & $\begin{array}{c}\text { Total } \\
\mathrm{n}=308(100 \%)\end{array}$ & $\mathrm{p}$-value \\
\hline Mask & $123(97 \%)$ & $32(82 \%)$ & $56(90 \%)$ & $74(92 \%)$ & $285(93 \%)$ & 0.045 \\
\hline Correctly worn & $107(87 \%)$ & $19(59 \%)$ & $37(66 \%)$ & $59(80 \%)$ & $222(78 \%)$ & 0.001 \\
\hline Cap & $127(100 \%)$ & $37(95 \%)$ & $61(98 \%)$ & $79(99 \%)$ & $304(99 \%)$ & 0.103 \\
\hline Correctly worn & $56(44 \%)$ & $14(38 \%)$ & $40(66 \%)$ & $35(44 \%)$ & $145(48 \%)$ & 0.02 \\
\hline Gloves & $127(100 \%)$ & $5(13 \%)$ & $19(31 \%)$ & $4(5 \%)$ & $155(50 \%)$ & 0.001 \\
\hline Clogs & $127(100 \%)$ & $39(100 \%)$ & $62(100 \%)$ & $66(82 \%)$ & $294(95 \%)$ & - \\
\hline Shoe covers & $17(13 \%)$ & $6(15 \%)$ & $2(3 \%)$ & $46(58 \%)$ & $71(23 \%)$ & 0.001 \\
\hline Scrubs & $127(100 \%)$ & $39(100 \%)$ & $62(100 \%)$ & $67(84 \%)$ & $295(96 \%)$ & - \\
\hline Gown & $127(100 \%)$ & $10(26 \%)$ & $12(19 \%)$ & $24(30 \%)$ & $173(56 \%)$ & 0.001 \\
\hline Eye protection & $34(27 \%)$ & $9(23 \%)$ & $11(18 \%)$ & $15(19 \%)$ & $69(22 \%)$ & 0.42 \\
\hline
\end{tabular}




\section{DISCUSSION}

Despite the implementation of measures to control surgical procedures and avoid infections, SSIs represent a frequent cause of morbidity and mortality in surgical patients. Numerous studies have shown that it is possible to reduce the risk of SSIs by adopting continuous surveillance programmes and by regular periodic feedback of findings $(15,16)$. It is vital that the measures laid down in guidelines are adopted in particular regarding the behaviour of staff working in the OR (13).

It is well known that the incorrect behaviour of health workers can lead to environmental contamination in the operating room and subsequent surgical site infection (17).

There are few and heterogeneous data in the literature on the behaviour of health professionals during surgery and the onset of surgical site infections (18). This study, conducted at the University Hospital G. Martino in Messina, Italy, showed significant discrepancies between the procedures actually implemented with those recommended by international guidelines. The reasons for these discrepancies fall outside the scope of this study but are undoubtedly complex. This issue therefore warrants further discussion and corrective measures.

Our study highlighted that during surgery the doors of the OR were opened frequently and that the number of personnel present in the OR was not tightly controlled. However, this last criticality occurs because the setting was a teaching hospital (with medical or nursing students). As it is vital to limit the number of OR staff and their movements to reduce bacterial contamination to a minimum, a review of the logistics and organisation of work is required $(9,19)$.

Our observations also revealed that face masks were not always correctly worn by OR staff despite the importance of doing so in order to significantly lower bacterial contamination of the surgical wound (20). As regards the head coverings, even this raised some critical issues relating to the covering being worn and/ or correct use. Studies in the literature have shown that use of headgear decreases the level of bacterial contamination in the air (21). Single-use surgical gowns were worn by surgeons in $100 \%$ of cases monitored in contrast with the very low percentage for other members of the team, nurses, anaesthetists and observers. It is well-known that the use of this garment is vital to reduce bacterial contamination. Indeed, the bacteria that reach the surgical site are mainly staphylococci coming from the cutaneous flora of people present in the $\operatorname{OR}(22,23)$.

Other studies have also shown the importance of the type of material used to make the gown: polyester garments offering greater protection than those made from polyester/cotton $(11,12)$. In our study the single use gowns were all made from polyester.

Shoe covers were worn by $23 \%$ of staff present in the OR, inasmuch as team members used surgical clogs exclusively used in the OR. There is no evidence in the literature demonstrating that shoe covers reduce the risk of SSI or lower bacterial load on the floor (24). However, we believe that they can protect the surgical team from exposure to blood or other fluids during the procedure.

\section{CONCLUSION}

Although in the literature there are conflicting opinions about the importance of surgical clothing in the prevention of ISS, the new and updated recommendations (25), based on evidence, reaffirm the importance of the use of the surgical mask, headgear, gown and sterile gloves.

In conclusion, our study demonstrates that in carrying out their duties not all healthcare workers comply with recommendations laid down in international guidelines for the prevention of surgical infections. For full compliance with the above guidelines it is important to provide OR personnel with continuous education and multidisciplinary measures regarding all phases of surgery. Measures should address hygiene and behaviour (hand hygiene, standard precautions), workplace hygiene (OR sanitation), organizational issues (rules for access to OR, operation checklist) and purely clinical matters (antibiotic prophylaxis, wound handling and medication).

In order to enhance safety and ensure the continuous improvement in healthcare provision, we believe that, in line with the literature (3), it is vital to monitor surgical teams continually and provide the team members with feedback on the results of audits thereby enabling risk factors to be reduced. We also recommend that re-audits should be undertaken to assess the effectiveness of remedial measures, to consolidate the improvements achieved and ensure that these continue over time.

\section{Conflict of Interests}

None declared

\section{REFERENCES}

1. European Centre for Disease Prevention and Control. Point prevalence survey of healthcare-associated infections and antimicrobial use in European acute care hospitals 2011-2012 [Internet]. Solna: ECDC; 2013 [cited 2019 Dec 8]. Available from: http://ecdc.europa.eu/en/publications/ Publications/healthcare-associated-infections-antimicrobial-use-PPS.pdf.

2. Reilly J, Twaddle S, McIntosh J, Kean L. An economic analysis of surgical wound infection. J Hosp Infect. 2001;49(4):245-9.

3. Ministry of Health. Training manual for clinical governance: patient and operator safety [Internet]. 2012 [cited 2019 Dec 8]. Available from: http:// www.salute.gov.it/imgs/C 17 pubblicazioni 1688 allegato.pdf.

4. Gaynes RP, Culver DH, Horan TC, Edwards JR, Richards C, Tolson JS. Surgical site infection (SSI) rates in the United States, 1992-1998: the National Nosocomial Infections Surveillance System basic SSI risk index. Clin Infect Dis. 2001 Sep 1;33 Suppl 2:S69-77.

5. Nichols RL. Preventing surgical sit infections: a surgeon's perspective. Emerg Infect Dis. 2001;7(2):220-4.

6. Mangram AJ, Horan TC, Pearson ML, Silver LC, Jarvis WR; Hospital Infection Control Practices Advisory Committee. Guideline for prevention of surgical site infection, 1999. Infect Control Hosp Epidemiol. 1999 Apr;20(4):247-80.

7. World Health Organization, World Alliance for Patient Safety. WHO guidelines for safe surgery [Internet]. Geneva: WHO; 2008 [cited 2019 Dec 8]. Available from: http://www.who.int/patientsafety/safesurgery/ knowledge_base/WHO_Guidelines_Safe_Surgery_finalJun08.pdf.

8. Pasquarella C, Sansebastiano GE, Ferretti S, Saccani E, Fanti M, Moscato $\mathrm{U}$, et al. A mobile laminar airflow unit to reduce air bacterial contamination at surgical area in a conventionally ventilated operating theatre. J Hosp Infect. 2007;66(4):313-9.

9. Parikh SN, Grice SS, Schnell BM, Salisbury SR. Operating room traffic: is there any role of monitoring it? J Pediatr Orthop. 2010 Sep;30(6):61723.

10. Sossai D, Dagnino G, Sanguineti F, Franchin F. Mobile laminar air flow screen for additional operating room ventilation: reduction of intraoperative bacterial contamination during total knee arthroplasty. J Orthop Traumatol. 2011 Dec;12(4):207-11.

11. Tammelin A, Ljungqvist B, Reinmüller B. Single-use surgical clothing system for reduction of airborne bacteria in the operating room. J Hosp Infect. 2013;84(3):245-7. 
12. Tammelin A, Ljungqvist B. Reinmüller B. Comparison of three distinct surgical clothing systems for protection from air-borne bacteria: a prospective observational study. Patient Saf Surg. 2012 Oct 15;6(1):23. doi: 10.1186/1754-9493-6-23.

13. Ministry of Labour, Health and Social Policies. Operating room safety manual: recommendations and checklist [Internet]. 2009 [cited 2019 Dec 8]. Available from: http://www.salute.gov.it/imgs/C_17_pubblicazioni_1119_allegato.pdf.

14. Demir $\bar{F}$. A survey on prevention of surgical infections in operating theaters. Worldviews Evid Based Nurs. 2009;6(2):102-13.

15. Geubbels EL, Nagelkerke NJ, Mintjes-De Groot AJ, VandenbrouckeGrauls CM, Grobbee DE, De Boer AS. Reduced risk of surgical site infections through surveillance in a network. Int J Qual Health Care. 2006;18(2):127-33

16. Gastmeier P, Geffers C, Brandt C, Zuschneid I, Sohr D, Schwab F, et al. Effectiveness of a nationwide nosocomial infection surveillance system for reducing nosocomial infections. J Hosp Infect. 2006;64(1):16-22.

17. Birgand G, Azevedo C, Toupet G, Pissard-Gibollet R, Grandbastien B Fleury E, et al. Attitudes, risk of infection and behaviours in the operating room (the ARIBO Project): a prospective, cross-sectional study. BMJ Open. 2014;4(1):e004274. doi: 10.1136/bmjopen-2013-004274.

18. Birgand G, Saliou P, Lucet JC. Influence of staff behavior on infectious risk in operating rooms: what is the evidence? Infect Control Hosp Epidemiol. 2015 Jan;36(1):93-106.

19. Scaltriti S, Cencetti S, Rovesti S, Marchesi I, Bargellini A, Borella P. Risk factors for particulate and microbial contamination of air in operating theatres. J Hosp Infect. 2007;66(4):320-6.
20. Alwitry A, Jackson E, Chen H, Holden R. The use of surgical facemasks during cataract surgery: is it necessary? Br J Ophthalmol. 2002;86(9):9757.

21. McHugh SM, Corrigan MA, Hill ADK, Humphreys H. Surgical attire, practices and their perception in the prevention of surgical site infection. Surgeon. 2014;12(1):47-52.

22. Baldini A, Blevins K, Del Gaizo D, Enke O, Goswami K, Griffin W, et al. General assembly, prevention, operating room - personnel: Proceedings of International Consensus on Orthopedic Infections. J Arthroplasty. 2019 Feb;34(2S):S97-S104.

23. Teter J, Guajardo I, Al-Rammah T, Rosson G, Perl TM, Manahan M. Assessment of operating room airflow using air particle counts and direct observation of door openings. Am J Infect Control. 2017 May $1 ; 45(5): 477-82$

24. Amirfeyz R, Tasker A, Ali S, Bowker K, Blom A. Theatre shoes - a link in the common pathway of postoperative wound infection? Ann R Coll Surg Engl. 2007;89(6):605-8.

25. Berríos-Torres SI, Umscheid CA, Bratzler DW, Leas B, Stone EC, Kelz RR, et al.; Healthcare Infection Control Practices Advisory Committee. Centers for Disease Control and Prevention guideline for the prevention of surgical site infection, 2017. JAMA Surg. 2017 Aug 1;152(8):784-91.

Received September 20, 2016 Accepted in revised form April 5, 2019 